\title{
Osteochondroma of femoral neck- a rare cause of femoro- acetabular impingement and sciatic nerve compression
}

\author{
Surojit Mondal ${ }^{1}$, Aniket Chowdhury ${ }^{2}$, Prasanta Kumar Mandal ${ }^{3}$, Dibakar Roy $^{4}$ \\ Subrata Pal ${ }^{5}$, Eashin $\mathrm{Gazi}^{6}$, Rakesh Kumar $^{7}$ \\ Department of Orthopaedics, B.S.Medical College,West Bengal,India ${ }^{1,3,4}$ \\ Department of Community Medicine, B.S.Medical College, West Bengal,India ${ }^{2,6,7}$ \\ Department of Pathology, B.S.Medical College, West Bengal,India ${ }^{5}$
}

\begin{abstract}
Osteochondroma or exostoses is most common Primary benign bone tumor and comprising of more than one-third of Primary benign bone tumors. They usually arise from metaphysis of long bone. They are mostly asymptomatic depending on their size and location. This article presents a noble case of Osteochondroma originating from the lesser trochanter of femur leading to development of mechanical blockade and sciatic neuropathy. Associated symptoms and radiographic findings were consistent with femoroacetabular impingement and sciatic nerve compression. A 26 year old female presented to our Orthopaedic clinic with complain of pain in left groin and tingling of left lower extremity for last one year. Radiographic finding was consistent with femoro-acetabular impingement caused by large proximal femoral Osteochondroma. Surgical en-bloc resection was performed and post-operatively symptoms resolved dramatically. Histopathological report confirmed the diagnosis of Osteochondroma .So we should aware of rare entities such as proximal femoral Osteochondroma during diagnosis and treatment of femoro-acetabular impingement syndrome and sciatic neuropathy along with other more common aetiology.
\end{abstract}

\section{Introduction}

Osteochondroma is a benign tumor containing both bone and cartilage, usually occurring near the end of long bone ${ }^{1}$.These tumors are overwhelmingly found as isolated lesion (90\%) though it can present as a part of multiple hereditary exostoses ${ }^{2}$.

Rains and Mann stated that Osteochondroma is almost certainly the result of a localized disturbance of bone growth at an epiphysis where by a portion of the epiphyseal cartilage remains in the periosteum of the metaphyseal segment of the bone and then endochondral ossification takes place in it, usually in continuity with the metaphyseal cortex and as the cartilage cap proliferates, endochondral ossification continues, resulting to growth of the osteochondroma and with continuous bone growth the osteochondroma moves away from the epiphysis and tends to become hooked, its tip pointing away from the epiphysis ${ }^{3 .}$

Müller believed that osteochondroma arise from a primary defect in periosteal differentiation in which ectopic collections of cartilage cells arise from the proliferative layer of the metaphyseal periosteum ${ }^{4}$.

Multipotent mesenchymal cells in the region of the perichondral groove of Ranvier have also been implicated in the development of osteochondromas ${ }^{5}$.

The osteal portion of osteochondroma provides only a supportive stroma since the ablation of the cartilage cap alone result in cessation of growth of the osteochondroma ${ }^{6}$.Osteochondroma grow until skeletal maturity; growth generally stops once the growth plates fuse though slow growth from the cap may continue over time, but this usually stops by age 30 years ${ }^{7}$.

Osteochondroma associated with multiple hereditary exostoses may present with limb length discrepancies, increased femoral ante version, valgus angulations and acetabular dysplasia .Solitary osteochondroma most commonly asymptomatic depending on their size and location very rarely solitary Osteochondroma linked with bursal inflammation, pain, compression of neurovascular structures and malignant degeneration ${ }^{8,9}$. The role of proximal femoral Osteochondroma in femoro-acetabular impingement syndrome and sciatic neuropathy very rarely reported in orthopedic literature. Osteochondroma of the femoral neck may lead to mechanical restriction of hip motion. Mechanical blockade can occur through direct contact of the widened and enlarged femoral neck against the ischium and acetabular rim. Non skeletal extrinsic complications can result from mass effect on the adjacent tissues including muscle, tendon, nerve and vascular structures. Nerve compression is rare and present in less than one percent of all cases of Osteochondroma. ${ }^{10}$

In this article we report a 26 years old female present with pain in left groin, weakness and tingling sensation of left lower extremity due to proximal femoral Osteochondroma. Radiograph shows cauliflower like mass originating from left proximal femur. This patient treated with surgical en-bloc resection and histopathology was diagnostic of Osteochondroma. 


\section{Case report:}

A 26 years old female presented with pain in left hip and pain and weakness of left lower extremity along with numbness and tingling in her toes and a palpable non-mobile mass in her left groin extending to left buttock for one year duration. There were no overlying skin changes or erythema and mass was non-tender on palpation. (Fig.-1) active hip flexion was limited to $90^{\circ}$. Further passive flexion was possible for $10^{\circ}$ but very painful. Adduction was limited to $10^{\circ}$ and extension $0^{\circ}$. Abduction was essentially normal, internal rotation was restricted to $15^{\circ}$. Strength was diminished for left Ankle dorsiflexion and plantar flexion. Sensation was diminished on plantar and dorsal aspect of foot. Radiography and CT shows a sessile cauliflower like mass measuring approximately $6 * 5$ centimeters attached to medial femoral neck and lesser trochanter and expand to antero-lateral and postero-lateral direction. (Fig-2, 3).

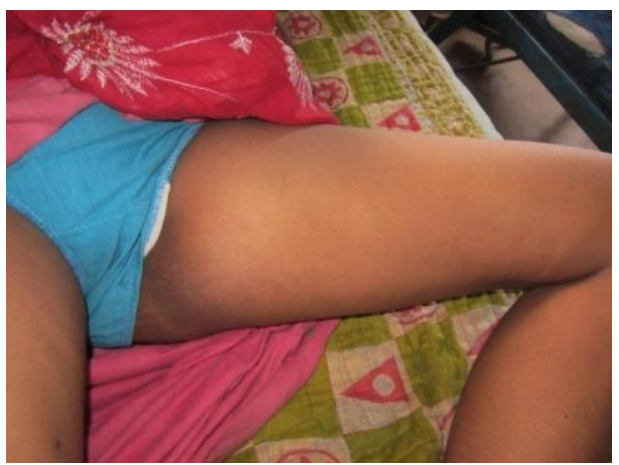

(Fig.-1) Showed large swelling in left groin without sign of overlying skin changes

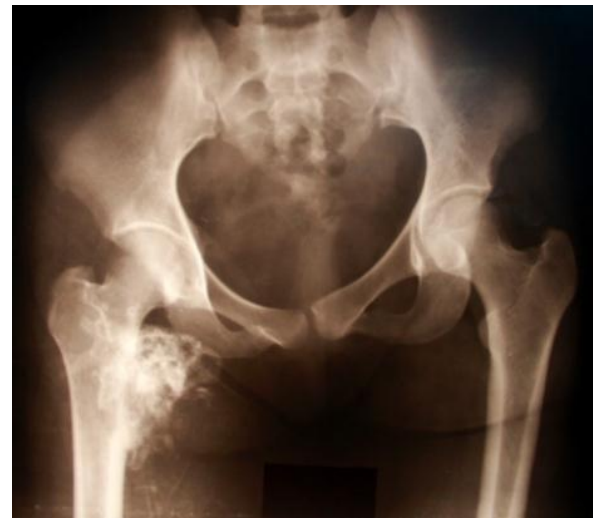

(Fig-2) A-P Radiograph of pelvis showed sessile cauliflower like attached to medial femoral neck and lesser trochanter and expand to antero-lateral and postero-lateral direction.

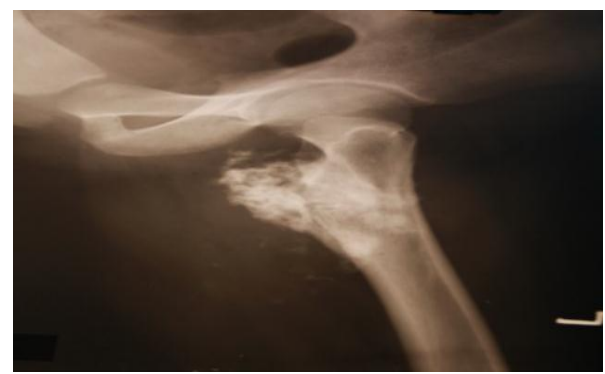

(Fig.-3) lateral radiograph showing the same 


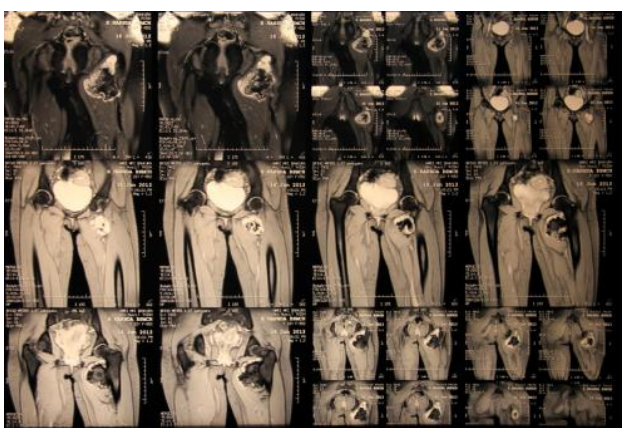

(Fig.-4) MRI of the hip demonstrates mass originating from lesser trochanter without any soft tissue extension and malignant degeneration but displace the adjacent muscle and sciatic nerve

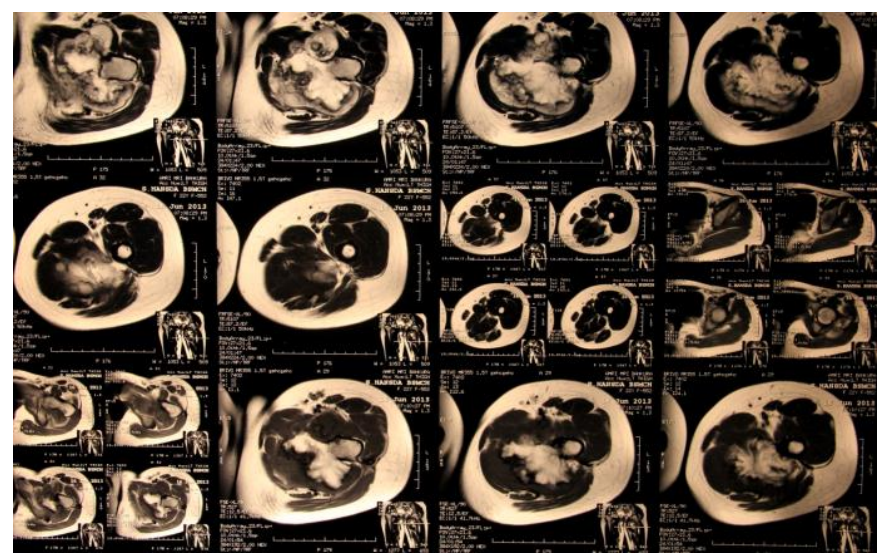

(Fig.-5) showing the same

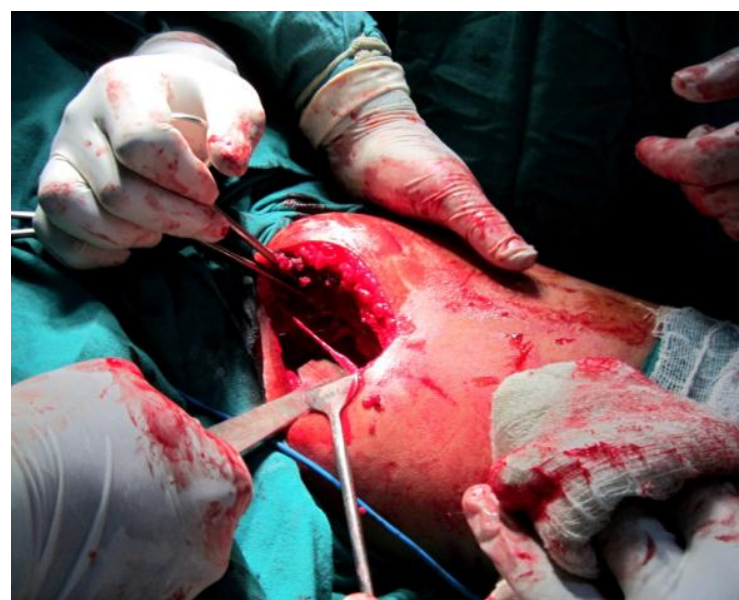

(Fig,6) showing surgical en block resection performed through Ludloff's approach 


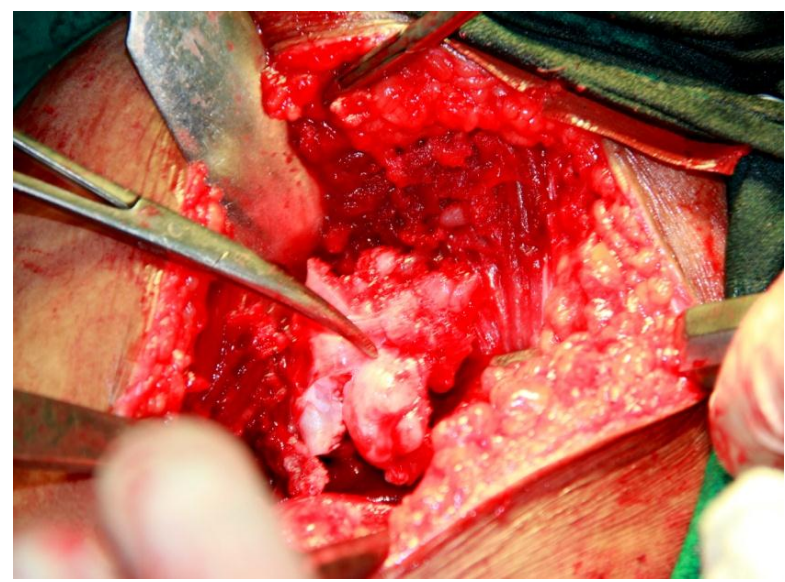

(Fig, 7) showing surgical en block resection performed through Ludloff's approach

MRI of the hip demonstrates mass originating from lesser trochanter without any soft tissue extension and malignant degeneration but displace the adjacent muscle and sciatic nerve. (fig4,5)

An electromyography study demonstrated sciatic neuropathy with peroneal and tibial component.

Pre -operative laboratory evaluation revealed a white blood cell count, differential count, erythrocyte sedimentation rate, $\mathrm{C}$ - reactive protein within normal limit.

Surgical en-bloc resection was performed under general anesthesia in supine position with left hip flexed, abducted and slightly externally rotated through Ludloff's approach. (Fig 7)

The final pathological report indicated the tumor as an Osteochondroma symptoms resolved dramatically following surgery. Patient reported improvement in numbness and tingling. Hip flexion increases to about $130^{\circ}$ at latest follow-up.

At 18 month follow up this patient had full resolution of her sciatic nerve motor and sensory findings. Radiograph of hip shows no evidence of osteoarthritis or avascular necrosis of head of the femur.

\section{Discussion}

The osteochondroma of femur originating from proximal left femur was solitary and sessile cauliflower like mass with its cortex continuous with cortex of the proximal femoral bone and also having homogeneous continuity with its medulla. Most solitary Osteochondroma discovered in children and adolescent are painless and present as slow growing mass. However depending on the location of Osteochondroma significant symptom may occur as a result of complications such as fractures, bony deformity, mechanical joint problem, vascular and neurological compromise and malignant transformation ${ }^{8,9}$.

Tanigawa et al were of the view that Osteochondroma developing around knee and hip are usually asymptomatic but can occasionally impinge surrounding vessels and nerves can cause various clinical manifestations. ${ }^{11}$

Femoral ante-version, impairment of hip flexion, acetabular dysplasia resulting in sublaxation of the hip, valgus deformity of the knee, and angular limb deformities are some of the defects commonly associated with Osteochondroma affecting proximal femur ${ }^{12}$.

The differential diagnosis of sciatic nerve compression was substantial and divided into Intraspinal, Extra-spinal, Pelvic and Extra pelvic categories of anatomic etiology ${ }^{13}$. Lumbar disc herniation and spinal canal stenosis are most common cause of sciatic nerve compression ${ }^{14}$. Other potential site includes the hip joint such as acetabulum, para-labral cyst, the pelvis as seen in impingement by the Obturator internus muscle, Pelvic bone tumors, such as Osteochondroma as in this case, female endometriosis and leiomyomas. ${ }^{15}$ Other less common cause of sciatic nerve compression includes vascular malformation, infectious disease ${ }^{15}$ and other tumors of bone and soft tissues. ${ }^{14,16}$

Hereditary multiple exostoses causes multiple bony projections with a cartilaginous cap. This bony exostoses have the potential to cause compression neuropathies but actual reported cases are rare. ${ }^{17}$

Turan Ilica et al reported a case of 34 years old man with femoral neck Osteochondroma that was causing sciatic nerve compression. CT and MRI were used to determine the size, origin and extent of the Osteochondroma and to plan strategies for surgery ${ }^{18}$.

In our case patient also demonstrated sign of sciatic nerve compression including weakness of the toe and ankle dorsiflexion and a diminished Achilles tendon reflexes. The Osteochondroma in that case as seen on 3D CT and MRI had a sessile structure and extended outward broadly in the region of lesser trochanter. This contracted with Osteochondroma presented here, which was substantially sessile, larger extended directly from femoral neck. 
The patient presented here, does not show any intraarticular hip pathology such as cartilage delamination or labral damage eliminating the need of trochanter osteotomy and surgical hip dislocation.

\section{Conclusion:}

To conclude Femoro-acetabular impingement and sciatic neuropathy can be due to various etiology. The syndrome may be a clinical manifestation of proximal femoral Osteochondroma very rarely. So during diagnosis of proximal femoral impingement syndrome we should take into accounts proximal femoral Osteochondroma. Surgical en-bloc resection protecting the surrounding neurovascular structure is a reliable means of treatment which resulting resolution of symptoms dramatically.

\section{References}

[1] Peterson HA. Multiple hereditary osteochondromata. Clin Orthop Relat Res. 1989; (239):222-230

[2] Edelman RR, Hesselink JR, Zlatkin MB. Vol. 3. Philadelphia: Saunders Elsevier; 2006. Clinical magnetic resonance imaging. pp. 2320-27

[3] Rains HA and Mann CV (1990) Tumours of bones and joints; in Bailey and love's short practice of surgery $20^{\text {th }}$ edition, HK Lewis pp 372-379.

[4] Müller E. Uber (1914). Hereditare multiple cartilaginare exostosen und exchondrosen. Beitr Pathol Anat.; 57:232.

[5] Mansoor A, Beals RK. (2007) Multiple exostosis: a short study of abnormalities near the growth plate. J Pediatr Orthop B. Vol. 16(5):363-5.

[6] Porter DE, Simpson AH (1999) The neoplastic pathogenesis of solitary and multiple osteochondromas. J Pathol. Vol ;188(2):119-25.

[7] Nogier A, De Pinieux G, Hottya G, Anract P (2006). Case reports: enlargement of a calcaneal osteochondroma after skeletal maturity. Clin Orthop Relat Res; 447:260-6.

[8] Matsumoto Y, Matsuda S, Matono K, et al.(2007) Intra-articular osteochondroma of the knee joint in a patient with hereditary multiple osteochondromatosis. Fukuoka Igaku Zasshi. Vol;98(12):425-30

[9] .Florez B, Mцnckeberg J, Castillo G, et al (2008). Solitary osteochondroma long-term follow-up. J Pediatr OrthopB. Vol;17(2):91-4

[10] Paik NJ, Han TR, Lim SJ. Multiple peripheral nerve compressions related to malignantly transformed hereditary multiple exostoses. Muscle Nerve. 2000; 23(8):1290-1294

[11] Tanigawa N, Kariya S, Kojima H, Komemushi A, Fujii H, Sawada S.(2007) Lower limb ischaemia caused by fractured osteochondroma of the femur. The British journal of radiology. Vol;80(952):e78-80

[12] Ali NK, Al-Salman MJ (2008) Osteochondroma and Osteochondromatosis. eMedicine Specialties<Orthopedic surgery. On line article

[13] Kulcu DG, Naderi S. Differential diagnosis of intraspinal and extraspinal non-discogenic sciatica. J Clin Neurosci. 2008; 15(11):1246-1252

[14] Bickels J, Kahanovitz N, Rubert CK, Henshaw RM, Moss DP, Meller I, Malawer MM. Extraspinal bone and soft-tissue tumors as a cause of sciatica. Clinical diagnosis and recommendations: analysis of 32 cases. Spine (Phila Pa 1976). 1999; 24(15):1611-1616

[15] Al-Khodairy AW, Bovay P, Gobelet C. Sciatica in the female patient: anatomical considerations, aetiology and review of the literature. Eur Spine J. 2007; 16(6):721-731

[16] Zonenshayn M, Edgar MA, Lavyne MH. Removal of a lumbar melanotic schwannoma via the far-lateral approach in a patient with Carney complex. Case report. J Neurosurg. 2000; 92(2 Suppl):241-245.

[17] Paik NJ, Han TR, Lim SJ. Multiple peripheral nerve compressions related to malignantly transformed hereditary multiple exostoses. Muscle Nerve. 2000; 23(8):1290-1294

[18] Turan Ilica A, Yasar E, Tuba Sanal H, Duran C, Guvenc I. Sciatic nerve compression due to femoral neck osteochondroma: MDCT and MR findings. Clin Rheumatol. 2008; 27(3):403-404 